\title{
A second trimester live tubal ectopic pregnancy: a case report
}

\author{
Kiran Kunwar*, Megha Punetha, Geeta Jain
}

Department of Obstetrics and Gynaecology, Government Medical College, Haldwani, Uttarakhand, India

Received: 07 August 2021

Accepted: 04 September 2021

\author{
*Correspondence: \\ Dr. Kiran Kunwar, \\ E-mail: kirankunwarkgmc@gmail.com
}

Copyright: (c) the author(s), publisher and licensee Medip Academy. This is an open-access article distributed under the terms of the Creative Commons Attribution Non-Commercial License, which permits unrestricted non-commercial use, distribution, and reproduction in any medium, provided the original work is properly cited.

\begin{abstract}
Ectopic or extra-uterine pregnancy occurs most commonly in fallopian tube. High index of suspicion is key to diagnose ectopic pregnancy in a pregnant-women presenting in first trimester with complains of amenorrhoea, pain in lower abdomen and vaginal bleeding. Such pregnancy can be managed by expectant, medically with methotrexate or surgically via laparoscopy or laparotomy if diagnosed promptly. In this case study, a 36-years-old, G2P1+0 presented in second trimester of pregnancy with pain in lower abdomen and vaginal bleeding. Her vitals were unstable and abdomen tender on palpation. Urgent ultrasound was done suggestive empty uterine cavity, a live 13 weeks 6 days fetus in left adnexa and hemoperitoneum suggestive ruptured tubal ectopic pregnancy. The patient's final diagnosis was live 13 weeks 6 days ruptured left tubal ectopic pregnancy which was managed by emergency laparotomy with a salpingectomy.
\end{abstract}

Keywords: Ectopic pregnancy, Ruptured tubal ectopic pregnancy, Hemoperitoneum

\section{INTRODUCTION}

An ectopic or extrauterine pregnancy is one in which the blastocyst implants anywhere other than the endometrial lining of the uterine cavity. ${ }^{1}$ The incidence of ectopic pregnancy is $1.5-2 \%$ of all pregnancies. ${ }^{2}$

Approximately 95\% ectopic implants occurred in fallopian tube and usually presents in first trimester. ${ }^{3}$ The classic triad associated with ectopic pregnancy are delayed menses $(74 \%)$, vaginal bleeding $(56 \%)$ and lower abdominal pain $(99 \%)$.

The management based upon the hemodynamic stability of patient, beta-hCG levels and size of the ectopic mass. Authors herein describes the unusual presentation of second trimester ectopic pregnancy.

\section{CASE REPORT}

A 36 years old lady $\mathrm{G} 2 \mathrm{P} 1+0$ presented to emergency department with complained of lower abdominal pain and vaginal bleeding associated with a history of amenorrhoea of four months. She was not registered for antenatal checkup anywhere. Her past obstetric history included a normal vaginal delivery 16 years back. Upon presentation, she complained of generalized lower abdominal pain which was sudden in onset, non-radiating and not relived by analgesic. There was no history of fainting attack or fever.

On clinical examination, the patient looked pale and tachypnoic. Her pulse rate was 120 beats per min with a blood pressure of $90 / 60 \mathrm{mmHg}$. Her abdomen was tender to touch suggestive of peritonitis. The bimanual examination was positive for cervical motion tenderness and pouch of douglas fullness present.

Urgent ultrasound was done which showed empty uterine cavity, a live fetus of 13 weeks 6 days by CRL in left adnexa and moderate amount of free fluid in pelvis (Figure 1 and 2). A provisional diagnosis of ruptured cornual horn was made looking the advanced gestational age and ultrasound report. Her hemoglobin was $5.8 \mathrm{~g} / \mathrm{dl}$ and urgent requisition for 4 blood units sent.

The patient was taken up for emergency laparotomy after taking written and informed consent from patient and her 
relative. During the laparotomy, a total of 31 of hemoperitoneum was suctioned. A 13 weeks fetus along with gestational sac and placenta were found along a ruptured left fallopian tube and removed from the pelvic cavity (Figure 3).

The left salpingectomy was done and the specimen sent for histopathological examination. Uterus and both the right and left ovaries were normal in morphology. Total 3 Packed red blood cells (PRBC) and 3 fresh frozen plasma (FFP) received during intra-operative period. She was shifted to intensive care unit for observation for days where her vitals was stable.

Repeat hemoglobin level was $7.8 \mathrm{~g} / \mathrm{dl}$ and 1 unit packed red blood cells transfused in post-operative day 2 . She was shifted back to gynac ward on postoperative day 3 and discharged in stable condition on day 5 after surgery.

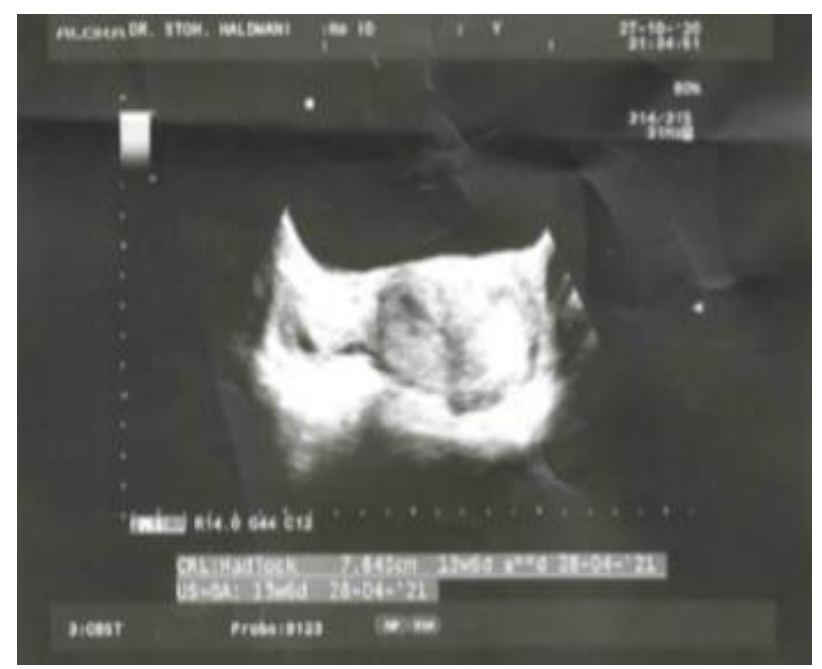

Figure 1: Transabdominal ultrasound showing empty uterine cavity.

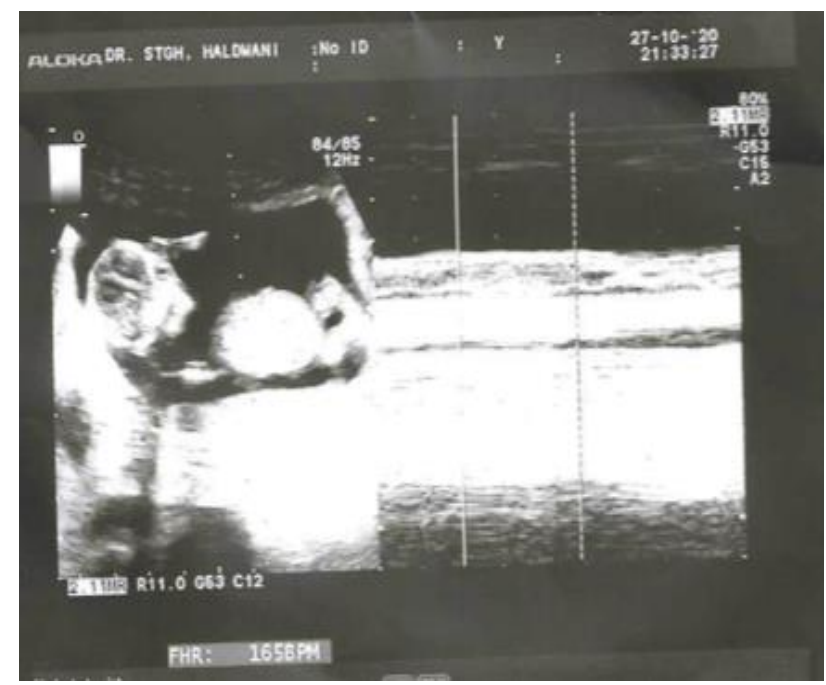

Figure 2: Transabdominal ultrasound showing fetus with cardiac activity (FHR 168 beats per min).

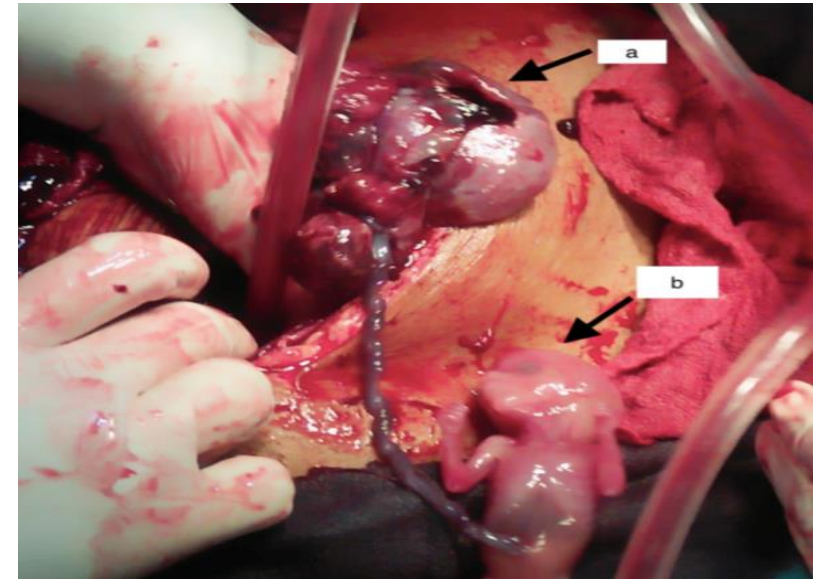

Figure 3: Intraoperative finding (a) ruptured ampulla of left fallopian tube; and (b) fetus attached to placenta.

\section{DISCUSSION}

Ectopic pregnancy is a major cause of maternal morbidity and mortality in first trimester of pregnancy as it is responsible for $9 \%$ to $13 \%$ of all pregnancy-related deaths. ${ }^{2}$ The ectopic pregnancy nearly $95 \%$ implants in fallopian tube and rest divided in ovarian (3\%), cervical $(<1 \%)$, abdominal $(1 \%)$ and cesearean scar $(<1 \%)$. Within fallopian tube, $70 \%$ of ectopic pregnancies are located in tubal ampulla, $12 \%$ in the isthmus, $11 \%$ in the fimbria and $2 \%$ in the interstitial segment. ${ }^{3}$

Almost half of the women does not have any risk factors for ectopic pregnancy, while rest of women have one or more recognized risk factors. ${ }^{4-6}$ The risk factors are prior history of ectopic pregnancy, history of infertility, genital tuberculosis, STIs and any tubal surgery such as salpinostomy, tubal recanalization. ${ }^{4-6}$

In approximately half of ampullary ectopic pregnancies, trophoblastic proliferation occurs entirely within the tubal lumen and the muscularis remain intact. ${ }^{8}$ In the remainder ,the trophoblast penetrates the tubal wall and proliferates in the loose connective tissue between the muscularis and the serosa ${ }^{8-10}$ In most cases, the characteristics segmental dilation of the tubal ampulla is composed mostly of coagulated blood rather than trophoblastic tissue. ${ }^{8}$ In contrast, ectopic implantations in the tubal isthmus typically penetrate the tubal wall relatively early, probably because the more muscular segment is less distensible. ${ }^{8}$

In most of the cases, the ectopic pregnancy presents in first trimester usually at 7.2 weeks \pm 2.2 with rupture leading to hemorrhage and shock. Although, cases have been reported in literature showing second or third trimester ectopic pregnancy as it is unusual for the fallopian tube to distend so much to accommodate advanced gestation. ${ }^{5}$

With biochemical investigation such as beta human chorionic gonadotrophin (BhCG) and skilled transvaginal 
sonography, ectopic pregnancy can be diagnosed early and plays an important role in expediting the management of patients. ${ }^{7}$ In our case, the patient presented in second trimester, there was least suspicion of ectopic pregnancy due to advance gestational age. Hence, urgent ultrasound was done suggestive of rupture ectopic with hemoperitoneum so the emergency laparotomy with left salpingectomy performed.

\section{CONCLUSION}

Although, it is rare for ectopic pregnancy to present at second trimester but it can occasionally happen. Thus, we should always keep high index of suspicion if a lady presents with classic triad of ectopic i.e.; amenorrhoea, pain in abdomen and vaginal bleeding as it is a lifethreatening condition. With the timely diagnosis and early management, we can reduce maternal morbidity and mortality.

Funding: No funding sources Conflict of interest: None declared

Ethical approval: Not required

\section{REFERENCES}

1. Bouyer J, Coste J, Fernandez H, Pouly JL, Spira N. Sites of ectopic pregnancy: a 10 year populationbased study of 1800 cases. Hum Reprod. 2002;17(12):3224-30.

2. Taran FA, Kagan KO, Hubner M, Hoopmann M, Wallwiener D, Brucker S. The Diagnosis and Treatment of Ectopic Pregnancy. Dtsch Arztebl Int. 2015;112(41):693-703.
3. Khalil MM, Shazly SM, Badran EY. An advanced second trimester tubal pregnancy: case report. Middle East Fertil Soc J. 2012;17:136-8.

4. Barnhart KT, Sammel MD, Gracia CR, Chittams J, Hummel AC, Shaunik A. Risk factors for ectopic pregnancy in women with symptomatic first-trimester pregnancies. Fertil Steril. 2006;86(1):36-43.

5. Gaskins AJ, Missmer SA, Edwards JW, Williams PL, Souter I, Chavarro JE. Demographic, lifestyle, and reproductive risk factors for ectopic pregnancy. Fertil Steril. 2018;110(7):1328-37.

6. American College of Obstetricians and Gynecologists. ACOG Practice Bulletin No. 94: Medical management of ectopic pregnancy. Obstet Gynecol. 2008;111(6):1479-85.

7. Alsuleiman SA, Grimes EM. Ectopic pregnancy: a review of 147 cases. J Reprod Med. 1982;27(2):1016.

8. Senterman M, Jibodh R, Tulandi T. Histopathologic study of ampullary and isthmic tubal ectopic pregnancy. Am J Obstet Gynecol. 1988;159(4):93941.

9. Budowick M, Johnson TR, Genadry R, Parmley TH, Woodruff JD. The histopathology of the developing tubal ectopic pregnancy. Fertil Steril. 1980;34(2):16971.

10. Dietl J, Buchholz F, Kindler PA. Histopathology of tubal pregnancy. Int $\mathrm{J}$ Gynaecol Obstet. 1988;27(3):385-8.

Cite this article as: Kunwar K, Punetha M, Jain G. A second trimester live tubal ectopic pregnancy: a case report. Int J Reprod Contracept Obstet Gynecol 2021;10:4005-7. 